\title{
Treatment of iatrogenic choriovitreal neovascularisation in sickle cell disease
}

\author{
R W Acheson, P D Fox, E L Chuang, G R Serjeant
}

\begin{abstract}
The effect of scatter photocoagulation on the perfusion of iatrogenic choriovitreal neovascularisation (CVN) has been assessed by a randomised trial in $35 \mathrm{CVN}$ lesions in 18 eyes with proliferative sickle retinopathy. No difference in size or vascularity of CVN lesions was apparent between the nine treated and nine control eyes over a median follow-up of 42 months. Scatter photocoagulation by the stated protocol was not effective in the treatment of CVN.
\end{abstract}

The vaso-occlusive process of sickle cell disease results in peripheral retinal ischaemia which may be associated with the development of proliferative sickle retinopathy (PSR). Treatment of PSR has been attempted by photocoagulation of the feeding arterioles in order to render these lesions avascular and therefore less prone to sight threatening complications. However, attempted closure of these feeding vessels requires high energy photocoagulation burns, which often disrupt Bruch's membrane. Ingrowth of choroidal vessels may result and is especially common following xenon arc photocoagulation. ${ }^{12}$ Choriovitreal neovascularisation.(CVN) has occurred in $53 \%$ of treated eyes. ${ }^{3}$ Choriovitreal neovascularisation may of itself lead to sight threatening complications including vitreous haemorrage, retinal traction, and retinal detachment. $^{34}$

Therapy of choriovitreal neovascularisation by direct photocoagulation of the lesion, ${ }^{12}$ cryotherapy or transscleral diathermy ${ }^{2}$ has been unsuccessful in achieving closure and has been

Accepted for publication 2 May 1991 associated with rapid enlargement of the lesion, vitreous haemorrhage, and traction detachment of the retina. ${ }^{2}$ In proliferative retinal vascular disease clinical evidence of a link between retinal ischaemia and retinal neovascularisation is well known. Hypotheses for the mechanism include the roles of retinal hypoxia, proteolytic enzymes on basement membrane collagen, insulin-like growth factors, and retina-derived growth factors. ${ }^{5}$ On the assumption that these influences induce and maintain the ingrowth of choroidal vessels the effect of local retinal ablation has been investigated.

\section{Patients and methods}

The patients attended the Sickle Cell Clinic at the University Hospital of the West Indies and had participated in two trials of xenon arc photocoagulation of PSR feeder vessels for which patients were enrolled during March 1973 to January $1977^{6}$ and April 1978 to September $1980 .^{7}$ Eighteen patients (mean age $38 \cdot 2$ years, range 21-61 years) were admitted to the present trial; their admission was based on signs of CVN on ophthalmoscopy and fluorescein angiography. Ten patients had sickle cell-haemoglobin C (SC) disease, six homozygous sickle cell (SS) disease, one sickle cell- $\beta \dagger$ thalassaemia, and one sickle cell- $\beta^{\circ}$ thalassaemia. Each patient contributed one eye to the trial, with a total of $35 \mathrm{CVN}$ lesions (single lesions in nine eyes, two lesions in four eyes, three in three eyes, four in a single eye, and five lesions in a single eye). The patients were recruited between March and September 1984; and after informed consent were randomly allocated to treatment or control groups by opening sealed envelopes. The nine eyes allocated to treatment contained $14 \mathrm{CVN}$ lesions all of which were treated, and the nine control eyes contained $21 \mathrm{CVN}$ lesions. All patients had assessment of corrected visual acuity, examination with indirect ophthalmoscopy, and fluorescein angiography concentrating on the early stages of dye transit to confirm the origin of blood supply for each CVN lesion.

The treatment protocol involved the creation of a 2-3 mm wide region of burns on the retina round the original burn scar but avoiding direct treatment to the CVN lesion, by applying argon laser burns of light to moderate intensity ( 212 to 584 in number, $400 \mu \mathrm{m}$ size, $0.1-0.2$ watt power, $0 \cdot 05-0 \cdot 1$ second duration) spaced 1 burn diameter apart (Fig 1). Scars near the ora serrata, where burns could not be placed anterior to the lesion, were surrounded by a horseshoe of burns laterally and posteriorly. All treated patients were asked to attend for review within one week to check for early complications, and then at 3,6, $9,12,15$ months and at $3-4$ years. One treated 
patient failed to attend for any review and could not be located. Three defaulted at, or had inadequate angiographic assessments after, nine months (control), 12 months (treatment), and 15 months (control). The remaining 14 eyes (seven treatment, seven control) were followed up for 3-4 years. In terms of individual CVN lesions no follow-up was possible for $4 \mathrm{CVNs} ; \mathrm{CVNs}$ were observed for 9 months, 4 for 12-15 months, and 23 for the 3-4 year period.

The outcome was assessed by changes in visual acuity and in perfusion on angiography. A drop in acuity of 2 lines or more on the Snellen chart (with Snellen lines 6/6, 6/9, 6/12, 6/24, 6/36, and $6 / 60$ ) for two consecutive visits at least three months apart was regarded as significant. Angiograms were examined by stereoscopic technique. An independent examiner (ELC) examined the angiograms but not the eyes to reduce observer bias. The response was defined as progression (increase in number or size of the previous capillary bed), regression (a decrease of the above), and cure (non-perfusion).

\section{Results}

In two control eyes vitreous haemorrhage reduced visual acuity, but this improved to normal with resolution of the haemorrhage within three months. The visual acuity in all other treated and control eyes remained unchanged.

Perfusion continued in all treated and control eyes. Of $11 \mathrm{CVN}$ lesions in each group with angiograms adequate for assessment of capillary structure the vessel systems increased in size in two treated cases and four controls, and remained stable or decreased in size in nine treated cases and seven controls, the difference failing to reach statistical-significance (Fisher's exact test, $\mathrm{p}=0 \cdot 31$ ).

\section{Discussion}

The rationale of the trial was based on the concept that the maintenance of choriovitreal neovascularisation may depend on humoral factors released by adjacent ischaemic retina. This assumption derived from the analogy to the effect of scatter photocoagulation in causing regression of retinal neovascularisation in retinal vein obstruction, ${ }^{8}$ and proliferative retinopathy associated with diabetes ${ }^{9}$ and sickle cell disease. ${ }^{10-12}$ The success of scatter photocoagulation in causing a prompt and sustained regression of choriovitreal neovascularisation developing after photocoagulation for choroidal melanomata ${ }^{13}$ is also consistent with this concept, though effects are likely to be due to photocoagulation of the tumour as well as the retina.

The present study suggests that scatter photocoagulation, as conducted by the stated protocol, has no effect in reducing the vascularity of iatrogenic choroidal neovascularisation in pro- liferative sickle retinopathy. This could imply either that the area of treated retina was insufficient to reduce a humoral stimulus to choroidal neovascularisation, that such a humoral stimulus was unnecessary for the maintenance of choroidal neovascularisation, or that another source of stimulation (such as the retinal pigment epithelium or choroid) was unaffected. Indeed the role of such humoral factors in the development and maintenance of both PSR and CVN is still unclear. With the exception of the regression of CVN lesions formed in the treatment of choroidal melanomata ${ }^{13}$ there is no evidence implying a humoral agent in the development or maintenance of CVN lesions.

Neovascular lesions arising from the choroid are difficult to render avascular: direct photocoagulation, ${ }^{12}$ cryotherapy, ${ }^{2}$ transscleral diathermy, ${ }^{2}$ and scatter photocoagulation have all be unsuccessful. However, although these lesions may appear large and sometimes increase dramatically in size, their effect on ultimate visual function is incompletely documented. Sight threatening complications may occur but fortunately are infrequent. ${ }^{34}$ The magnitude of risk to vision appears to be no worse than in eyes with PSR alone. ${ }^{4}$

Consideration of the potential complications of photocoagulation - for example, that this condition is iatrogenic-necessitate a conservative approach to this generally benign condition.

We thank Professor L Jampol and Mr P Condon for their advice in the conduct of this trial, Miss Susan Ford for her help with the photography, and Dr Mary Codd for statistical analysis.

1 Condon PI, Jampol LM, Ford SM, Serieant GR. Choroida neovascularisation induced by photocoagulation in sickle neovascularisation induced by photocoagula
cell disease. $\mathrm{Br}$. Ophthalmol $1981 ; 65: 192-7$.

2 Dizon-Moore RV, Jampol LM, Goldberg MF. Chorioretina and choriovitreal neovascularisation. Arch Ophthalmol 1981 99: 842-9.

3 Fox P, Acheson RW, Serjeant GR. The outcome of iatrogenic choroidal neovascularisation in sickle cell disease. $\mathrm{Br} f$ Ophthalmol 1990; 74: 417-20.

4 Carney MD, Paylor RR, Cunha-Vaz JG, Jampol LM, Goldberg MF. Iatrogenic choroidal neovascularisation in sickle cell retinopathy. Ophthalmology 1986; 93: 1163-8.

5 Frank RN. Etiologic mechanisms in diabetic retinopathy. In: Ryan SJ, ed in chief. Retina. Murphy RB, Patz A, Schachat AP, eds. Medical Retina St Louis; Mosby, 1989: 301-26.

6 Condon PI, Serieant GR. Photocoagulation in proliferative sickle retinopathy: results of a 5-year study. Brf Ophthalmol $1980 ; 64: 832-40$.

7 Jampol LM, Condon PI, Farber M, Rabb M, Ford S, Serjeant GR. A randomised clinical trial of feeder vessel photocoagulation of proliferative sickle cell retinopathy. 1 . Preiminary results. Ophthalmology 1983; 90: 540-5.

8 Krill AE, Archer D, Newell FW. Photocoagulation in complications secondary to branch vein occlusion. Arch Ophthalmol 1971; 85: 48 .

9 Diabetic Retinopathy Research Group. Photocoagulation treatment of proliferative diabetic retinopathy: the second report of Diabetic Retinopathy Study findings. Ophthalmology 1978; 85: 82-106.

10 Hanscom TA Indirect treatment of peripheral retinal neovascularisation. Am $\mathcal{F}$ Ophthalmol 1982; 93: 88-91.

11 Rednam KRV, Jampol LM, Goldberg MF. Scatter retinal photocoagulation for proliferative sickle retinopathy. $A m \mathcal{F}$ Ophthalmol 1982; 93: 594-9.

12 Kimmel AS, Magargal LE, Stephens RF, Cruess AL. Peripheral circumferential retinal scatter photocoagulation for the treatment of proliferative sickle retinopathy. An update. Ophthalmology 1986; 93: 1429-34.

13 Augsberger JJ, Piro PA, Shields JA, Magargal LE, Donoso LA. Scatter photocoagulation for choroidovitreal neovascularisation. Retina $1984 ; 4$ : $171-6$. 